\title{
A ESCOLA JESUÍTICA E A PRODUÇÃO SACRA NO GRÃO-PARÁ E MARANHÃO
}

\author{
Moema de Bacelar Alves \\ Universidade Federal do Pará
}

A Companhia de Jesus se estabeleceu nos territórios do Maranhão e GrãoPará na primeira metade do século XVII, sendo a terceira Ordem Religiosa a se estabelecer na região ${ }^{1}$. Mais precisamente, esses religiosos chegaram à cidade de São Luis em 1618 e em Belém só se instalam definitivamente no ano de 1653.

A ordem dos jesuítas foi a maior e mais rica ordem a atuar na Amazônia, merecendo destaque também a sua relação com os indígenas ${ }^{2}$. Porém, a partir do processo de laicização pelo qual estavam passando os Estados Nacionais na Europa, as Ordens Religiosas foram perdendo espaço de atuação e poder junto à sociedade. A própria Companhia de Jesus já havia sido expulsa da região antes da expulsão definitiva realizada pelo Marquês de Pombal - primeiro-ministro de D. José I - , em 1759.

Todavia, o que nos interessa aqui é a ação das escolas jesuíticas na produção de arte sacra dessas capitanias. Temos conhecimento de que esses religiosos foram os principais responsáveis não só pela catequese, mas também pelo ensino de ofícios aos indígenas e noviços, a princípio, ficando ao encargo dos padres - aptos para executarem diversos ofícios - a transmissão, entre outras, das práticas de pintura e escultura.

A estratégia usada para converter os gentios era repassar os preceitos anti-luteranos necessários à afirmação da Igreja Católica através do ensino de música, teatro e ofícios manuais. Nesse entender, seduzir os sentidos dos índios era mais fecundo que explorar suas habilidades intelectuais. Através das imagens, as barreiras lingüísticas e conceituais eram aliviadas. Ao mesmo tempo, os primeiros missionários acreditavam que por

\footnotetext{
1 Neste primeiro momento vieram quatro ordens religiosas para a região: franciscanos, carmelitas, jesuítas e mercedários. A ordem de chegada desses religiosos é a mesma para as duas capitanias, havendo diferença apenas nas datas: Franciscanos (1614 e 1617); Carmelitas (1615 e 1626); Jesuítas (1618 e 1653); Mercedários (1654 e 1639) - as datas estão dispostas respectivamente no Maranhão e Grão-Pará.

${ }^{2} \mathrm{O}$ que acabou gerando alguns desentendimentos entre os religiosos da Companhia de Jesus e os colonos, posto que os primeiros defendiam a liberdade dos indígenas por os verem como seres humanos, já os segundos os tinham enquanto força de trabalho.
} 
meio dessas práticas se dava o melhor método para "amansar" o selvagem indígena. Essa forma de catequese foi reforçada pelo Concilio de Trento quando ordenou que os:

(...) Bispos ensinem, pois, diligentemente, com narrações dos ministérios de nossa redenção, com quadros, pinturas e outras figuras, pois assim se instrui e confirma o povo, ajudando-o a venerar e recordar assiduamente os artigos de fé3.

O casamento da catequese com o ensino de ofícios aos habitantes locais foi o principal responsável pela peculiaridade das obras. Tanto na ornamentação das igrejas, quanto nas esculturas sacras de forma geral, sente-se o toque indígena. Ainda que fiéis às características básicas para o reconhecimento de determinada cena ou santo, as imagens trazem uma carga de subjetivismo que dão particularidade à produção. Os artistas indígenas não apenas observaram e copiaram os modelos ocidentais ensinados nas escolas, mas também reinterpretaram e adaptaram esses modelos, ocasionando numa arte mais desprendida dos critérios estilísticos adotados pelos europeus ${ }^{4}$. Aliás, as características mais acentuadas da arte brasileira são mais facilmente identificadas em peças isoladas do que na decoração de interiores, uma vez que nas primeiras os artesãos possuem maior autonomia para criar, para se expressar.

Essa pedagogia - se é que podemos usar este termo - foi acompanhada do barroco, estilo que, pelo próprio apelo emocional que carrega, serviu de mecanismo de evangelização, obedecendo ao intuito de tocar e convencer os indígenas da fé cristã. Sua gesticulação expressiva funcionou como forte aliada à doutrinação. A Igreja mesclava seus interesses à apelação característica do barroco. A opulência dos púlpitos, altares e até paredes inteiras repletas das mais variadas formas, tais como: conchas, anjos e outras simbologias, de imediato captam nossa atenção e é justamente essa a intenção nas pregações. Toda uma encenação ritualística envolvendo visão, oralidade e música era montada para fixar os fiéis à mensagem que estavam passando. A finalidade de tamanho espetáculo era

3 APUD Kátia Santos Bógea; Emanuela Sousa Ribeiro; Stella Regina Soares de Brito. Olhos da Alma: Escola Maranhense de Imaginária. São Luis, 2002. p. 21.

4 O historiador francês Serge Gruzinski, em uma análise muito elucidativa, trabalha justamente com as reinterpretações feitas pelos ameríndios do México, bem como as adaptações de cenas e imagens à sua mitologia pré-colombiana. Nessa perspectiva, os pintores mexicanos, por não possuírem - a principio - noção da pintura européia e por estarem distantes da evolução de estilos, tinham desvantagens técnicas, mas também relativa liberdade de criação. Ver: Serge Gruzinski. O Pensamento Mestiço. São Paulo: Companhia Das Letras, 2001. p. 108. 
impressionar e ainda hoje, quando entramos em qualquer igreja barroca, sentimos a força das imagens, somos tocados por sua carga dramática e muitas vezes passamos um longo tempo analisando a graça de tamanha riqueza de detalhes. É realmente impossível ficar indiferente diante de uma obra barroca!

\section{Os Colégios de Santo Alexandre e Nossa Senhora da Luz}

Sem desconsiderar a importância da propagação de ofícios aprendidos nas escolas jesuíticas por seus ex-aprendizes ${ }^{5}$, nos Colégios de Santo Alexandre, em Belém, e Nossa Senhora da Luz ${ }^{6}$, em São Luis, funcionavam as duas oficinas que comprovadamente ensinavam as práticas artísticas. Dependentes desses colégios, podemos citar o Seminário de Nossa Senhora das Missões e a Casa Colégio de Vigia, ligados ao colégio do Pará, e a Casa de Exercícios e de Campo da Madre de Deus, Casa-Colégio de Alcântara e os seminários menores de Aldeias Altas e Parnaíba, ligados ao do Maranhão .

Como visava a auto-suficiência, a Companhia de Jesus procurava aproveitar todos os recursos locais, tanto de materiais quanto de mão-deobra, para a confecção das imagens sacras. Dessa forma, ensinava as práticas em marcenaria, carpintaria, entalhe e escultura nas oficinas de artes e ofícios, juntamente com o ensino das letras. A produção local se favorecia pela abundância de madeira e da tabatinga - argila que após um processo de cozimento era usada em substituição ao gesso ${ }^{8}$. Para as obras de talha, a madeira mais cobiçada era o cedro "dito branco" e podemos ressaltar o amplo uso desses materiais enquanto diferenciador das imagens produzidas

5 Também não devemos deixar de citar a mobilidade social gerada pela qualificação dos indígenas. Uma vez chegando a ser oficial, estava mais suscetível a ascender socialmente, visto que suas habilidades se igualavam a dos oficiais brancos.

6 Atual Igreja da Sé.

7 Kátia Santos Bógea; Emanuela Sousa Ribeiro; Stella Regina Soares de Brito. Op. Cit. p. 21.

8 A saber: tabatinga em tupi significa barro branco.

9 Em uma relação de madeiras enviada à Portugal, o cedro aparece - ao lado de mais de vinte madeiras - na categoria dos que servem para taboados, obras de casas e outros diferentes usos, tendo a seguinte nota: também para obras de talha. Relaçaõ das madeiras do Estado do Grão-Pará que até o presente se tem reconhecido as mais proprias para a construcção de embarcaçoens; para moveis de casa; e para outros diffentes usos; estraihida de outra similhante relaçao que em carta de 15 de septembro de 1777, derigio o Illm ${ }^{\circ}$ e Exm ${ }^{\circ}$ Senhor Joao Pereira Caldas, sendo Governador e Capitao General do Estado, à Secretaria de Estado dos Negocios da Marinha e Dominios Ultramarinos. Arquivo Público do Estado do Pará, Caixa da Biblioteca Nacional, Pasta 2, Documento 1. 
na colônia das feitas em Portugal. Além disso, a busca de materiais para as peças acabava por favorecer a integração entre as oficinas do Grão-Pará e Maranhão ${ }^{10}$.

Dentre os pintores e escultores das capitanias do Grão-Pará e Maranhão destacam-se: Frei João Xavier Traer, que veio para Belém de uma região que hoje pertence à Itália; o irmão Francisco Rebelo, Frei Luis Correia e Frei Agostinho Rodrigues, todos portugueses, tendo o primeiro se situado em Vigia (PA) em meados do século XVIII, e os outros dois em Belém. Já no Maranhão temos a forte influência de Manuel Manso ${ }^{11}$ e Diogo de Sousa (ambos portugueses) e do índio Francisco, que veio da Bahia em fins do século XVII depois de já ter trabalhado nas obras de marcenaria da igreja dos jesuítas dessa localidade. Como vemos, em diversas ocasiões temos a convivência de mestres estrangeiros portugueses em maioria - não só com indígenas da própria região, mas também de outros lugares. Esse intercâmbio de informação e técnicas possibilitou a criação de imagens originais, geradas por meio da combinação de diferentes culturas.

Com a já referida expulsão das ordens religiosas, as mudanças artísticas começaram a ganhar espaço e o espírito barroco foi perdendo seu vigor. Novas necessidades e interpretações foram ganhando corpo. Como vimos, até então a produção da imaginária local era dirigida pelos colégios jesuítas, que estabeleciam os cânones artísticos a serem trabalhados por seus discípulos. Os religiosos acompanhavam rigidamente a iconografia trabalhada e as técnicas utilizadas.

É nesse contexto que surge a Escola Maranhense de Imaginária. A partir dela se tem a origem do chamado Barroco Maranhense, produzido por artesãos que haviam aprendido os ofícios de entalhadores e escultores com os mestres jesuítas e agora se viam mais livres para pôr em prática características próprias, criando traços particulares capazes de identificar a peça com a escola.

\section{Algumas características da produção dos séculos XVII e XVII}

Com relação às esculturas, podemos dizer que as imagens do século XVII são mais austeras, característica do maneirismo, como ainda o uso do

\footnotetext{
${ }^{10}$ Kátia Santos Bógea; Emanuela Sousa Ribeiro; Stella Regina Soares de Brito. Op. Cit. p. 24.

${ }^{11}$ Este foi responsável pela feitura do retábulo da Igreja de Nossa Senhora da Luz.
} 
panejamento vertical e a simplicidade das expressões faciais. Do mesmo modo, já apresentam uma movimentação tímida, percebida, por exemplo, na ondulação dos cabelos. Essa descrição é bastante visível em uma imagem do Cristo Morto - importante representação cristã - datada do final do século XVII'12.

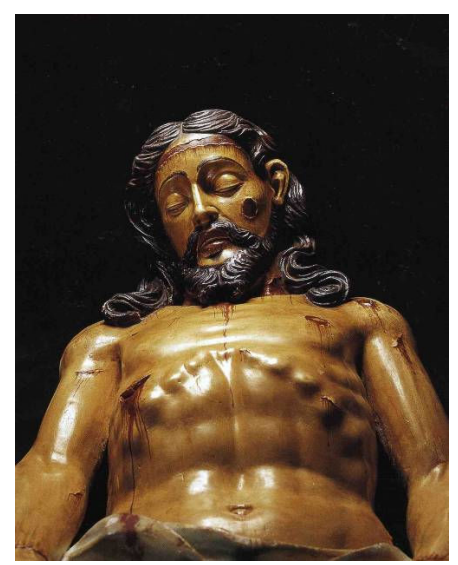

Cristo Morto. Foto: Edgar Rocha

O setecentos representou o auge do barroco na colônia e isso pode ser visto na maior ornamentação das peças. O panejamento passa a apresentar curvas e contracurvas, dando ar de movimentação, a face é sempre dramática com expressões de paixão e dor, a carnação é de muito naturalismo, além de ser significativa a prática da policromia e douramento. Ao analisar as imagens desse período, percebemos que ao longo do século as feições vão sendo feitas com mais detalhe, seus gestos e expressões vão se tornando mais suaves. Um exemplo dessa produção é uma imagem de Santana Mestra, datada do século XVIII. As feições dessa imagem apresentam características do tipo físico local e expressam atenção, compaixão. Sua vestimenta apresenta detalhes em flores, douramento e certa movimentação, mostrando maior cuidado no tratamento da imagem ${ }^{13}$.

\footnotetext{
12 Esta imagem é pertencente ao acervo de São Luis. Kátia Santos Bógea; Emanuela Sousa Ribeiro; Stella Regina Soares de Brito. Op. Cit. p. 25.

${ }^{13}$ Imagem pertencente ao Museu de Arte Sacra de Pará. PARÁ, Secretaria Executiva de Cultura do Estado. Feliz Lusitânia/Museu de Arte Sacra. Belém: SECULT, 2005. Série Restauro.
} 


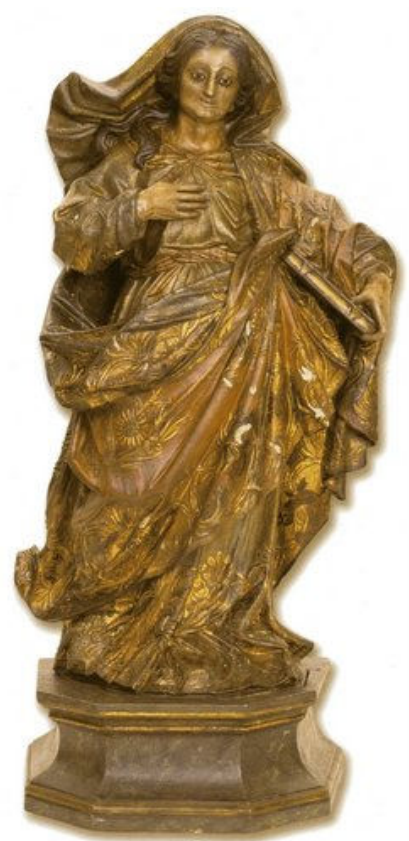

Santana Mestra. Imagem retirada do livro Feliz Lusitânia/Museu de Arte Sacra. Belém, 2005.

A produção de esculturas e imaginária alternava entre as imagens dos mais diversos santos e de Jesus. No caso das representações deste e de Virgem Maria, as várias fases de suas vidas eram retratadas, numa interpretação clara das passagens bíblicas onde as leituras eram apresentadas principalmente para aqueles que não sabiam ler mas que precisavam conhecer os paradigmas do cristianismo. Já no tocante aos santos, a produção era realizada de acordo com as necessidades de devoção do momento. Destacamos aqui a figura do Cristo crucificado, representação base da iconografia cristã e que ocupava lugar de relevo nos altares mores.

$\mathrm{Na}$ decoração de interiores, iconografias como conchas, guirlandas de rosas, girassóis, ramalhetes, golfinhos, anjos, folhas de acanto e volutas eram amplamente aplicadas em altares, púlpitos e pinturas de teto. Interessante é notar os ajustes da iconografia à realidade local. $\mathrm{O}$ pelicano, ave constante da simbologia cristã por representar o amor paternal, é por vezes substituído por araras ou papagaios, numa clara adaptação à nossa fauna. 
Um exemplo dessa produção barroca são os retábulo e púlpitos da Igreja de Santo Alexandre, em Belém, antiga igreja dos jesuítas inicialmente dedicada a Santo Inácio de Loiola. Germain Bazin, ao se referir aos púlpitos e retábulo desta, diz que se trata de "uma traça muito erudita", porém sua execução indica certa ingenuidade, produto talvez da mão-de-obra indígena ${ }^{14}$.

\section{Conclusão}

De forma geral, o Brasil do século XVIII é marcado ainda pela explosão do rococó, porém, não podemos dizer que a produção do Grão Pará e Maranhão tenha a mesma decoração ostentosa de outras regiões, como Minas Gerais, por exemplo. Assim como a policromia das imagens era mais rudimentar e discreta que de outras escolas de imaginária e as pinturas de teto menos exuberantes.

Condicionadas pelos valores cristãos de uma sociedade religiosa que precisava expandir sua fé em resposta à Reforma Protestante, a talha e a pintura representam os aspectos mais significativos da arte colonial brasileira. No cenário das artes, o século XVIII é bastante significativo, sendo inclusive considerado o momento em que a produção colonial atinge seu apogeu e a imaginária brasileira se liberta da realizada pela metrópole. $\mathrm{O}$ aumento de escolas regionais, após a expulsão das ordens religiosas fez com que os artistas leigos (dentre eles muitos indígenas e mestiços) tomassem a frente da produção não só no Maranhão, como citamos acima. Esse fato naturalmente implicou em modificações de algumas características escultóricas; a exemplo do tipo físico do caboclo, que passa a ser mais reproduzido nas imagens ${ }^{15}$.

${ }^{14}$ Germain Bazin. A arquitetura religiosa barroca no Brasil. Rio de Janeiro: Editora Record, 1956. p. 325.

${ }^{15}$ Ao longo do texto foi enfatizada a produção de esculturas e altares, porém não podemos deixar de citar a importância das pinturas. É comum vermos nas igrejas grandes telas retratando santos ou passagens bíblicas. Sejam nos alteres mores ou laterais, a imponência dessas imagens é tão forte quanto das esculturas. Normalmente encomendadas a pintores de renome, em maioria europeus com destaque para Portugal. A reprodução pictórica não se tratava apenas de ornamentação, uma vez que também seguia ao intuito didático de aproximação dos fiéis aos preceitos católicos. Dessa forma, os analfabetos leriam nas imagens o que não podiam ler na Bíblia. 


\section{Bibliografia}

ABRIL CULTURAL (Ed.). Arte no Brasil. São Paulo: Editora Abril, 1979. 2 v.

ÁVILA, Affonso; GONTIJO, João Marcos M.; MACHADO, Reinaldo Guedes. Barroco mineiro: glossário de arquitetura e ornamentação. São Paulo: Companhia Melhoramentos de São Paulo, 1980;

BAZIN, Germain. A arquitetura religiosa barroca no Brasil. Rio de Janeiro: Editora Record, 1956;

BÓGEA, Kátia Santos; RIBEIRO, Emanuela Sousa; BRITO, Stella Regina Soares de. Olhos da Alma: Escola Maranhense de Imaginária. São Luis, 2002.

FORLINE, Louis Carlos; MURRIETA, Rui Sérgio Sereni; VIEIRA, Ima Célia Guimarães (Org.). Amazônia além dos 500 anos. Belém: Museu Paraense Emílio Goeldi, 2005.

GURZINSKI, Serge. O Pensamento Mestiço. São Paulo: Companhia Das Letras, 2001.

OLIVEIRA, Myriam Andrade Ribeiro de. O rococó religioso no Brasil e seus antecedentes europeus. São Paulo: Cosas \& Naify, 2003.

PARÁ, Secretaria Executiva de Cultura do Estado. Feliz Lusitânia/Museu de Arte Sacra. Belém: SECULT, 2005. Série Restauro. 3v.;

SOBRAL, Maria de Lourdes Sampaio. As missões religiosas e o barroco no Pará. Belém: UFPA, 1986;

TIRAPELI, Percival (org.). Arte Sacra Colonial: Barroco Memória Viva. São Paulo: Editora UNESP, Imprensa Oficial do Estado, 2001. 